ISSN: 0514-7336

DOI: http://dx.doi.org/10.14201/zephyrus2016777998

\title{
LAS HERRAMIENTAS PREHISTÓRICAS DE LAS MINAS DE VARISCITA DE PALAZUELO DE LAS CUEVAS (ZAMORA) Y PICO CENTENO (HUELVA). ANÁLISIS COMPARATIVO
}

\section{Prebistoric mining tools of the variscite mines of Palazuelo de las Cuevas (Zamora) and Pico Centeno (Huelva). A comparative analysis}

\author{
Rodrigo Villalobos García* y Carlos P. Odriozola Lloret**
}

* Dpto. de Prehistoria, Arqueología, Antropología Social y CC y TT Historiográficas. Facultad de Filosofía y Letras. Univ. de Valladolid. Plaza del Campus, s/n. 47011 Valladolid. Correo-e: rodrigovillalobosgarcia@gmail.com

** Dpto. de Prehistoria y Arqueología. Facultad de Geografía e Historia. Univ. de Sevilla. C/ María de Padilla, s/n. 41004 Sevilla. Correo-e: codriozola@us.es

Recepción: 9/04/2015; Revisión: 6/02/2016; Aceptación: 20/03/2016

REsumen: Se presentan las herramientas prehistóricas de minería recuperadas en prospecciones y excavaciones de las minas de variscita de Palazuelo de las Cuevas (Aliste, Zamora) y Pico Centeno (Encinasola, Huelva). Los útiles de piedra tallada no son raros en los contextos mineros prehistóricos peninsulares aunque, probablemente debido a que aparecen con poca frecuencia, no han despertado gran interés. Aquí planteamos una aproximación a las características morfológicas y capacidades tecnológicas de estos artefactos mediante el análisis de las unidades tecnofuncionales. A través de la identificación de características como la técnica de obtención, la forma y la funcionalidad de las distintas zonas de un útil, junto con la valoración de su distribución a lo largo de la pieza y la constatación de la presencia o ausencia de huellas de uso, creemos posible averiguar el modo de utilización de estos objetos. Así, hemos identificado que los mineros prehistóricos diseñaron y emplearon herramientas compuestas o multifuncionales. Al comparar el utillaje de ambos distritos mineros creemos haber encontrado suficientes diferencias como para hablar de dos tradiciones tecnológicas independientes que, según se argumenta, creemos que son debidas a que las minas zamoranas fueron explotadas a una escala mayor.

Palabras clave: Península Ibérica; Prehistoria Reciente; Arqueología de la Minería; macro-utillaje; Unidad Tecno-Funcional.

Авsтract: This paper shows the prehistoric mining tools recovered during the archaeological field-walking surveys and excavations of the variscite mines of Palazuelo de las Cuevas (Aliste disctrict, Zamora) and Pico Centeno (Encinasola, Huelva). Knapped stone mining tools are not absent of the Iberian prehistoric mines, but they appear in low frequency and, probably for that reason, had not attracted scholars' attention. A way to inquire on the morphological characteristics and technological qualities of these objects is through the so called analysis of techno-functional units. Technique, shape, function, and use-wear distributions are identified along the artefact's techno-functional units in order to propose how these tools were used. This approach shows, among other aspects, how ancient miners designed and used multifunctional tools. Regarding the comparison of the ensembles from these two mining districts there are enough differences as for considering them as two independent technological traditions. It is argued that these differences are most probably related to the different scale of production calculated between Palazuelo de las Cuevas and Pico Centeno.

Key words: Iberian Peninsula; Late Prehistory; Mining Archaeology; Ground stone tools; Techno-Functional Unit.

(C) Universidad de Salamanca

Zephyrus, LXXVII, enero-junio 2016, 79-98 


\section{Introducción}

La variscita es un raro mineral verde que fue profusamente empleado durante la Prehistoria Reciente de Europa Occidental para la elaboración de adornos personales (Forde, 1930; Roscian et al., 1992; Villalba et al., 2001) y que en la Península Ibérica sólo cuenta con tres afloramientos de entidad tal como para ser susceptibles de ser explotados: aquellos que se localizan en la comarca de Aliste
(Zamora) (Arribas et al., 1971) y en los municipios de Gavà (Barcelona) (Alonso et al., 1978) y Encinasola (Huelva) (Moro Benito et al., 1991). Hasta el momento sólo se habían estudiado con detenimiento las evidencias arqueológicas de minería prehistórica en el caso de los filones barceloneses (Villalba et al., 1986; Bosch y Borrell, 2009), entre cuyas publicaciones se cuentan, lógicamente, descripciones de los útiles mineros (Villalba et al., 1986: cap. 7; Bofill y Borrell, 2009). Recientes intervenciones, tanto
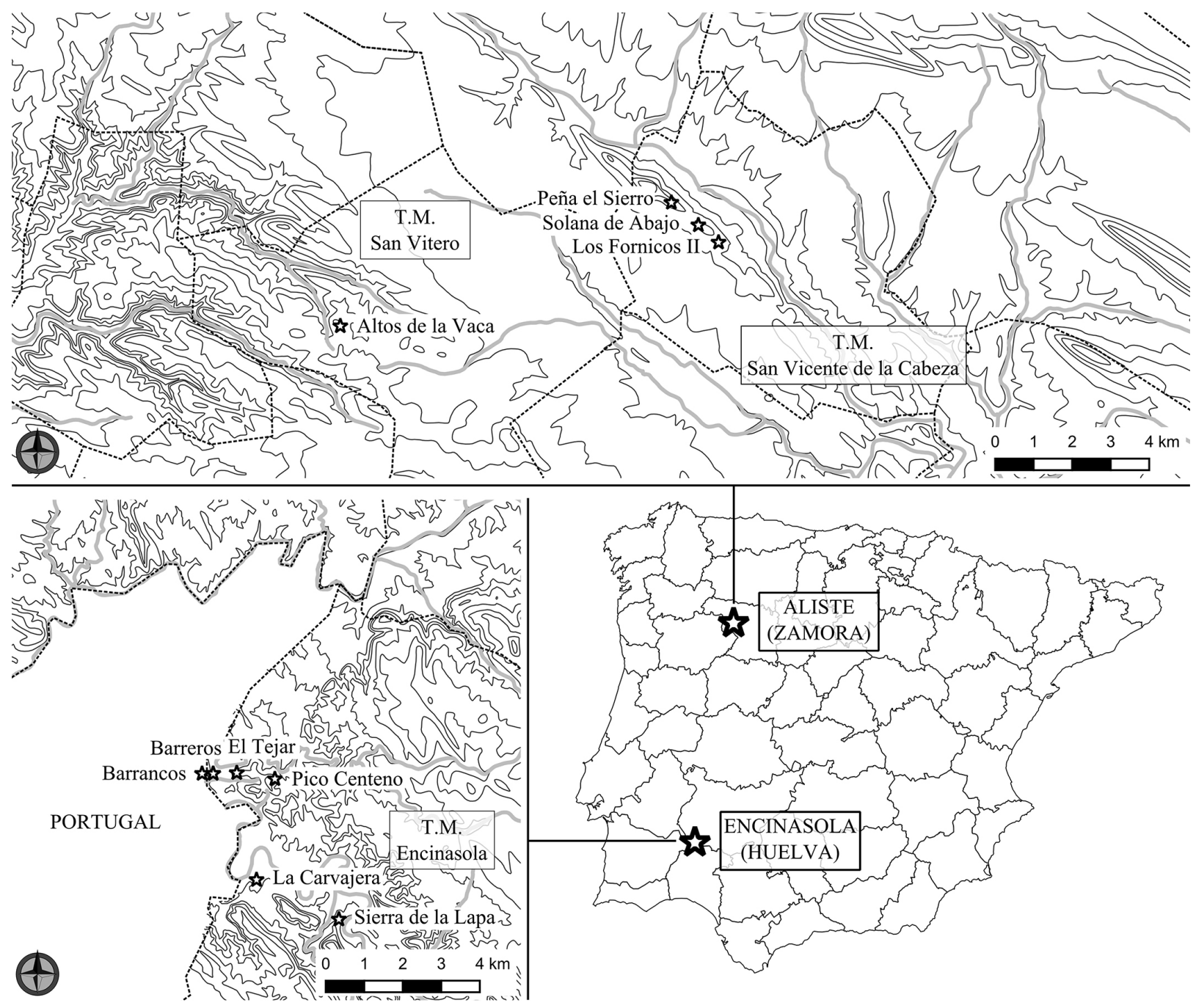

Fig. 1. Localización de los distritos mineros de variscita de Aliste y de Pico Centeno en la Península Ibérica con los respectivos mapas de detalle que muestran la distribución de los yacimientos que han deparado útiles mineros (cartografía elaborada a partir de la BTN 100 (C) Instituto Geográfico Nacional de España). 
en las minas de Zamora como en las de Huelva ${ }^{1}$, han permitido recuperar varios lotes de artefactos relacionados con las actividades mineras, por lo que el objetivo de estas páginas es presentar los resultados de un análisis de su encuadramiento cronológico, morfología y capacidades tecnológicas (Fig. 1).

\section{Contextualización arqueológica del instrumental de las minas de variscita a estudiar}

\subsection{Las minas de la comarca de Aliste (Zamora)}

A finales de la década de los años 60 del s. xx se descubrieron los afloramientos de variscita de $\mathrm{Pa}$ lazuelo de las Cuevas y otros lugares de la comarca zamorana de Aliste en los cuales, además, se identificó la existencia de minas antiguas (Arribas et al., 1971; Campano Lorenzo et al., 1985; Fernández Turiel et al., 1992). Recientes trabajos han retomado el estudio de estas evidencias arqueológicas, y sus resultados se pueden sintetizar en que, aunque se constaten pruebas de extracción de variscita en distintos puntos de la comarca, es en los cerros de Las Cercas (Palazuelo de las Cuevas) y La Cogolla (Palazuelo de las Cuevas/San Vicente de la Cabeza) donde se concentra la mayor parte de las minas -de tipo trinchera, pozo y galería (Villalobos García y Odriozola, 2016)-². Éstas fueron resultado de la actividad extractiva de minerales verdes desarrollada principalmente durante la Prehistoria Reciente (Villalobos y Odriozola, 2016) y época romana (Gutiérrez Pérez et al., 2015).

${ }^{1}$ Las últimas prospecciones y excavaciones de las minas de variscita de Zamora y Huelva han sido financiadas por la Junta de Castilla y León - "La explotación minera de variscita durante el Neolítico y Calcolítico en el sinclinal de Alcañices (Zamora)"- y la Junta de Andalucía - "El patrimonio histórico minero de Andalucía”-.

2 También Villalobos, R. y Odriozola, C. P.: "Las minas de variscita de la comarca de Aliste (Zamora, España)". En VIII Cong. Int. Minería y Metalurgia en el Sudoeste Europeo. Presente y futuro de los paisajes mineros del pasado: estudios sobre mineria, metalurgia y poblamiento. Granada, en prensa.
En directa relación espacial con el filón de mineral y las minas identificadas se ha recuperado en superficie cerca de un centenar de artefactos de piedra tallada que procede de cuatro yacimientos distintos, a saber: Peña el Sierro $(n=40)$, Solana de Abajo $(\mathrm{n}=2)$, Los Fornicos II $(\mathrm{n}=53)$ y Altos de la Vaca $(n=1)$. Peńa El Sierro se halla en la ladera suroriental del cerro de Las Cercas (Palazuelo de las Cuevas), Solana de Abajo en la ladera noroccidental del cerro de La Cogolla (Palazuelo de las Cuevas), Los Fornicos II en la ladera suroriental del Cerro de la Cogolla (Palazuelo de las Cuevas/San Vicente de la Cabeza) y el artefacto de Los Altos de la Vaca procede del cerro del mismo nombre (San Vitero) (Fig. 1, arriba). A excepción del objeto de Los Altos de la Vaca, que fue recuperado en la excavación arqueológica de un pozo que perforaba la roca encajante de la variscita, todos los artefactos fueron recogidos en prospecciones de superficie. No obstante, la aplicación de una prueba de correlación espacial ${ }^{3}$ muestra que la distribución de estos útiles está relacionada de forma estadísticamente significativa con la ubicación de minas y mineral, lo que nos sirve como prueba para defender que los objetos de Peńa El Sierro, Solana de Abajo y Los Fornicos II también participaron en las actividades de minado de los cerros de Las Cercas y La Cogolla.

\subsection{Las minas de Encinasola (Huelva)}

En la década de los años 80 del s. xx se identificaron filones de variscita en el cerro de Pico Centeno, en la localidad onubense de Encinasola (Moro et al., 1991), y pocos años después se documentaron en este lugar varias minas antiguas (Nocete y Linares, 1999). Al igual que en el caso zamorano, las intervenciones arqueológicas actuales han servido para descubrir nuevos afloramientos y pruebas de su minado en varios puntos del área circundante, cuya explotación tuvo lugar en distintos momentos, entre ellos la Prehistoria Reciente (Odriozola et al., 2010, 2016; Odriozola y Villalobos, 2015).

${ }^{3}$ Cf. Villalobos y Odriozola, op. cit. n. 2, fig. 2. 
Los casi setenta artefactos recuperados en esta zona proceden de diferentes yacimientos. En prospección se recogieron junto a las minas y puntos de extracción de Pico Centeno Mina $2(\mathrm{n}=8)$, Barrancos $(n=1)$, Barreros $(n=1)$, La Carvajera ( $n$ $=1)$, Sierra de la Lapa $(\mathrm{n}=2)$ y El Tejar $(\mathrm{n}=3)$. La totalidad de estos yacimientos se localiza en los cerros entre los que serpentea el río Múrtigas a su paso por el municipio de Encinasola (Fig. 1, abajo izquierda). A esto debemos ańadir los artefactos procedentes de la excavación arqueológica de Pico Centeno Mina $2(\mathrm{n}=50)$.

\subsection{Adscripción cronológica de los útiles}

Debido al contexto de recuperación de los artefactos, bien en la propia excavación de la trinchera de extracción de variscita en el caso de Pico Centeno, o dispuestos a lo largo del filón de variscita y las distintas minas en el caso de Palazuelo de las Cuevas, consideramos probado que se encuentran vinculados directamente con la actividad de extracción de este mineral verde. En la Península Ibérica, además del uso de variscita durante la Prehistoria Reciente que antes hemos citado, también se conoce su aprovechamiento en época romana $(\mathrm{Gu}-$ tiérrez Pérez et al., 2015) y, de forma esporádica, en la Edad Moderna (Garcia-Guinea et al., 2000). Asimismo, dataciones radiocarbónicas y osL de la trinchera de Pico Centeno indican una frecuentación intermitente de este lugar entre el Neolítico y la época de la "fiebre del cobre" decimonónica (Odriozola et al., 2016).

Dado que ni el periodo de uso de la materia prima explotada ni las dataciones absolutas de la citada mina permiten adscribir estos útiles a una época concreta, es mediante la tipología comparada como hemos encarado este problema. El hecho de que sea un instrumental minero elaborado en su totalidad en piedra es tenido generalmente como indicativo de su cronología prehistórica, pero debemos apuntar que la perduración de determinadas herramientas pétreas durante momentos posteriores, ya históricos, es una cuestión que todavía se debate, tal y como sucede con el caso del clásico martillo acanalado ( $c f$. Hunt, 2003: 281-283; Domergue, 2008:
96-100; Blas y Suárez, 2009). No obstante, entre los utensilios que aquí presentamos no se encuentra ningún martillo acanalado ni similar sino que, como describiremos a continuación, son un conjunto de objetos configurados principalmente mediante la talla para la obtención de extremos afilados y/o apuntados. Herramientas de este tipo se documentan en la Península Ibérica en minas neolíticas de sílex (Capote, 2011; Tarriño et al., 2011) y variscita (Villalba et al., 1986), y también en algunos casos de minas calcolíticas de cobre (Hunt, 2003: 119-120), pero desaparecen del registro material a partir de la generalización del instrumental minero de hierro durante la segunda mitad del I milenio cal a. C. (Craddock, 1995: 47-48, 63-67 y 71-73; Hunt, 2003: 283; Montero, 2010).

Por tanto, debido a que con anterioridad al I milenio cal a. C. el único momento en el que en el occidente peninsular se utilizó de forma generalizada la variscita fue durante el Neolítico y el Calcolítico (Villalobos García y Odriozola, 2016: fig. 7), consideramos muy probable que los conjuntos de herramientas de Pico Centeno y Palazuelo de las Cuevas que aquí presentamos fueran diseñados y utilizados fundamentalmente durante el IV y iII milenios cal a. C.

\section{Los artefactos para la extracción de variscita de Zamora y Huelva. Características morfológicas, tecnológicas y tipológicas}

Para el análisis de las características de los conjuntos de herramientas mineras hemos tomado aquellos que ofrecen una muestra de mayor tamaño, y que son los de Peña el Sierro (Ps) y Los Fornicos II (F) de Zamora y el de Pico Centeno Mina 2 (PC) de Huelva. De ellos hemos seleccionado aquellas piezas 1) conclusas - pues, como se verá más adelante, existen elementos en proceso de elaboración- y 2) completas -es decir, no rotas-. Por tanto, a excepción de en el epígrafe 3.4.3, a lo largo de los siguientes párrafos excluiremos conscientemente los materiales en proceso de elaboración y rotos a la hora de cuantificar la cantidad de objetos con presencia/ ausencia de los distintos atributos en relación con el total de artefactos de cada conjunto. Así, la cantidad 
de herramientas consideradas para cada yacimiento será de 40 para Peña el Sierro, 53 para Los Fornicos II y 40 para Pico Centeno Mina 2.

\subsection{Materia prima, dimensiones y peso}

En todos los casos, y aún a falta de análisis petrográficos, hemos identificado la cuarcita como la materia prima más utilizada. Sobre esta roca se

\begin{tabular}{|l|c|c|c|c|c|c|c|c|}
\hline \multirow{2}{*}{ Conjunto } & \multicolumn{2}{|c|}{ Altura $(\mathrm{mm})$} & \multicolumn{2}{c|}{ Anchura $(\mathrm{mm})$} & \multicolumn{2}{c|}{ Espesor $(\mathrm{mm})$} & \multicolumn{2}{c|}{ Peso $(\mathrm{g})$} \\
\cline { 2 - 9 } & $\overline{\mathrm{x}}$ & $\mathrm{s}$ & $\overline{\mathrm{x}}$ & $\mathrm{s}$ & $\overline{\mathrm{x}}$ & $\mathrm{s}$ & $\overline{\mathrm{x}}$ & $\mathrm{s}$ \\
\hline Peńa el Sierro $(\mathrm{n}=40)$ & 122 & 25 & 84 & 12 & 38 & 8 & 456 & 153 \\
\hline Los Fornicos II $(\mathrm{n}=53)$ & 121 & 28 & 82 & 15 & 39 & 10 & 512 & 273 \\
\hline Pico Centeno PCM2 $(\mathrm{n}=40)$ & 133 & 34 & 95 & 21 & 53 & 15 & 1079 & 633 \\
\hline
\end{tabular}

Fig. 2. Medidas de centralidad (media, $\bar{x}$ ) y dispersión (desviación estándar, $s$ ) de las variables métricas de los conjuntos de artefactos.

encuentran elaborados el 100\% de los útiles de Los Fornicos II, el 98\% de los de Peńa el Sierro y el 79\% de los de Pico Centeno. Si bien en el entorno inmediato de los yacimientos la cuarcita no aflora de forma natural, los mapas geológicos MAGNA ${ }^{4}$ muestran que tanto en el caso zamorano como en el onubense ésta es asequible a menos de un par de kilómetros, junto a los cauces de los ríos Aliste y Múrtigas, respectivamente. Otras materias primas que hemos creído identificar igualmente de visu son, a nuestro entender, rocas sedimentarias de tipo conglomerado y/o arenisca y algún ejemplar de chert.

$\mathrm{Al}$ respecto de los soportes, en todos los yacimientos nos encontramos con objetos elaborados tanto sobre núcleos como sobre lascas, pero podemos decir que en los tres casos la mayoría de los utensilios fue realizada sobre núcleos. Del total de artefactos en los que pudo identificarse adecuadamente el tipo de soporte hemos determinado que se elaboraron a partir de núcleos el 54\% de los útiles de Peña el Sierro, el $60 \%$ de los de Los Fornicos in y el 90\% de los de Pico Centeno. A partir de tales soportes se procedió a la configuración del utillaje minero principalmente a través de la talla, técnica que se identifica en el $100 \%$ de los útiles de Peña el Sierro y Fornicos II y en el $85 \%$ de los de Pico Centeno. El 15\% restante de los artefactos de Pico Centeno se trabajó mediante el piqueteado, una técnica que no aparece en ningún caso en los materiales de los yacimientos zamoranos.

\footnotetext{
${ }^{4}$ Nos referimos en concreto a las hojas 338 (Alcañices) y 895 (Encinasola) de los Mapas Geológicos de España a escala 1:50.000 y sus respectivas memorias, disponibles para su consulta en www.igme.es.
}

Sobre las variables de dimensiones y peso podemos apuntar que los tres casos presentan unos valores similares en cuanto a altura y anchura pero que difieren en cuanto a espesor y peso (Fig. 2). Al respecto de estas dos últimas hay que destacar que, mientras que los útiles zamoranos de Peña el Sierro y Los Fornicos II se mueven en unos valores similares, son los onubenses de Pico Centeno los que muestran unos valores que, al ser comparados con los demás, ofrecen diferencias estadísticamente significativas 5 . Esto se traduce en que aunque los tres conjuntos muestren una silueta similar $-c .125 \mathrm{~mm}$ de altura y $90 \mathrm{~mm}$ de anchura medias- es, gracias a su mayor espesor, por lo que los artefactos de Pico Centeno son marcadamente más pesados -de media $c .500 \mathrm{~g}$ los artefactos zamoranos frente a los $c$. $1000 \mathrm{~g}$ los onubenses-.

\subsection{El problema de encontrar una tipología adecuada para caracterizar los útiles mineros prehistóricos}

Hay varias materias primas minadas durante la Prehistoria reciente de la Península Ibérica como son, además de la ya citada variscita, sílex (Ramos, 1998; Capote et al., 2008; Tarrińo et al., 2011),

5 La aplicación de una serie de pruebas estadísticas de significación "t de Student" y "U de Mann-Whitney” mediante el software "Past 3.0" nos ofrece valores $\mathrm{p}<0,01 \mathrm{al}$ comparar los pesos y la anchura de los conjuntos de útiles de Pico Centeno con los de Peńa el Sierro y con los de Los Fornicos II, pero no al comparar los de Los Fornicos II con los de Peńa el Sierro. Esto habla a favor de la semejanza entre sí de los conjuntos zamoranos y de su diferencia con el conjunto onubense. 
cobre (Hunt, 2003; Blas, 2011) o sal (Abarquero y Guerra, 2010). Al respecto de las herramientas empleadas en esas labores podemos encontrarnos con picos de asta de ciervo o con alguna posible cuña metálica (Blas y Suárez, 2009), pero, como ya mencionamos, lo más habitual en estos contextos son los utensilios de piedra. De estos los más conocidos son los martillos acanalados, habituales en minas prehistóricas de cobre (Blanco Freijeiro y Rothenberg, 1981; Domergue, 1990: 115-118; Hunt, 2003: 281-285; Blas, 2011), aunque también se cita la presencia esporádica de hachas pulimentadas (Delibes de Castro et al., 2003; Hunt, 2003: 47, 52 y 286; Hunt et al., 2011).

Sin embargo, hay otro tipo de útiles que se caracterizan por ser piedras trabajadas de formas que incluyen preferentemente la talla y, en ocasiones, también el piqueteado (Blanco Freijeiro y Rothenberg, 1981: fig. 39; Capote, 2011: fig. 2; Tarriño Vinagre et al., 2011: 26), y que en la literatura arqueológica suelen denominarse de forma vaga como 'martillos', 'cuñas', 'picos', etc. Esto no es algo exclusivo de la Prehistoria peninsular, y en otros yacimientos europeos se han propuesto a tal efecto clasificaciones tipológicas que quieren distinguir 'martillos' de 'herramientas de machacado' y 'picos o cuñas', entre otros (Timberlake y Craddock, 2013). Sin embargo, al tratar de aplicarlas a nuestro caso de estudio hemos comprobado que resultan demasiado rígidas, pues entre los útiles de Palazuelo de las Cuevas o de Pico Centeno es posible encontrar configuraciones que, como describiremos, permiten que una misma pieza haya podido funcionar al mismo tiempo como pico y como cuña o como martillo.

\subsection{El análisis de Unidades Tecno-Funcionales}

Debido a la imposibilidad de adscribir nuestros útiles mineros a las distintas categorías propuestas hemos optado por realizar una clasificación no dirigida hacia el tipo de artefacto sino hacia los tipos de las varias partes funcionales con que contaría cada utensilio. Desde hace tiempo se aplica a las herramientas del Paleolítico inferior y medio y de forma más reciente al utillaje macrolítico de la Prehistoria Reciente el llamado análisis de Unidades
Tecno-Funcionales (UTF), el cual se enfoca hacia la caracterización de las distintas zonas de un útil "que se singularizan por sus capacidades funcionales propias y homogéneas” (Donnart, 2010: 181). Así, se distinguen UTF de contacto transformativo (UTF CT), como aquellas obtenidas para actuar directamente sobre la materia a transformar; UTF de contacto prensil (UTF CP), como aquellas preparadas para el enmangue o agarre de la herramienta, y UTF de contacto receptivo de energía (UTF CR), como aquellas adecuadas para recibir mediante el golpeo la energía que permita el correcto funcionamiento del útil (Donnart, 2010: 181).

Una vez clasificada la función de las unidades se plantea el distinguir la técnica de obtención de las mismas. De este modo se diferencian UTF naturales de transformadas ${ }^{6}$; entre las segundas se separan UTF no conformadas de conformadas ${ }^{7} ; y$, de estas últimas, se discriminan utf no talladas de talladas $^{8}$ (Donnart, 2010: 183). De un modo ya más desdibujado se plantea caracterizar la delineación o forma de la UTF. Aquí introducimos nuestra propia clasificación, pues para el caso que nos ocupa nos hemos encontrado con UTF de formas planas, convexas, afiladas, apuntadas y en escotadura (Fig. 3).

Para realizar una caracterización lo suficientemente representativa del utillaje empleado en la minería de variscita del occidente peninsular hemos seleccionado para su análisis los artefactos de aquellos yacimientos que nos han ofrecido una muestra de mayor tamaño, que son los de los lugares zamoranos de Peña el Sierro y Los Fornicos II y los del onubense de Pico Centeno Mina 2. Hemos representado una selección de los mismos en las Figs. 4 a 6, en donde señalamos las UTF identificadas de modo que su función, técnica y forma aparecen consignadas con el código función/técnica/forma según las claves de las distintas categorías que se expresan en la Fig. 3. El lector interesado en consultar los dibujos de la totalidad de los artefactos aquí tratados puede acceder a ellos

\footnotetext{
6 Transformée en el original.

Façonnée en el original.

8 Taillée en el original.
} 
\begin{tabular}{l|ll} 
& UTF según función & $\begin{array}{ll}\text { de Contacto Transformativo } \\
\text { de Contacto Prensil } \\
\text { de Contacto Receptivo de energía }\end{array}$ \\
\end{tabular}

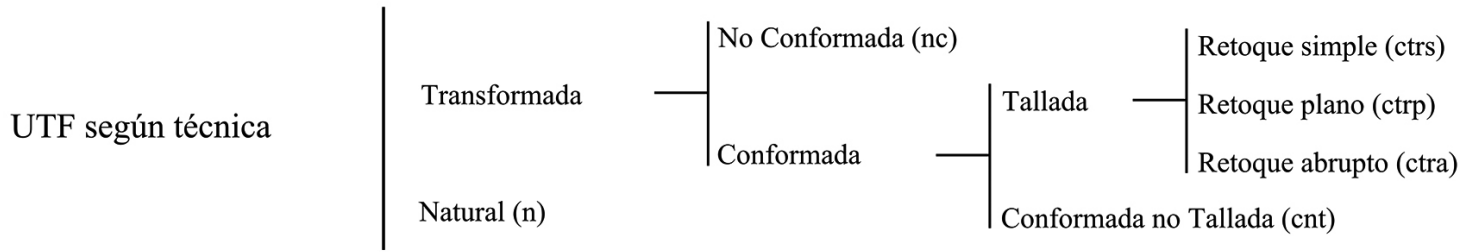

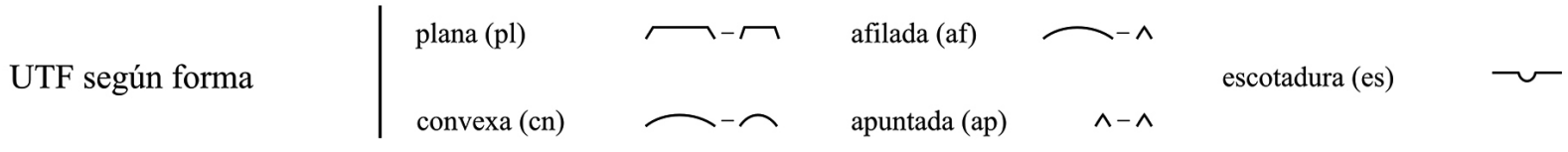

FIG. 3. Esquema de clasificación de Unidades Tecno-Funcionales por función, técnica y forma.

on-line 9 . De este modo una UTF "CT/ctrs/ap" será aquella cuya función sería el "Contacto Transformativo" (СT), su técnica la "conformada tallada por retoque simple" (ctrs) y su forma "apuntada" (ap); una "UTF $\mathrm{CR} / \mathrm{n} / \mathrm{pl}$ ” será en la que la función sería el "Contacto Receptivo de energía" (CR), su técnica ninguna, esto es, el uso de la superficie "natural" (n), y su forma "plana" (pl); como último ejemplo, una UTF “CP/cnt/es” será una UTF cuya función sería el "Contacto Prensil” (CP), su técnica la "conformada no tallada", que generalmente suele ser mediante piqueteado (cnt), y su forma "escotadura" (es). Además, hemos complementado las representaciones de las distintas huellas de uso apreciables de visu en cada una de las herramientas, empleando líneas en zigzag para simbolizar bordes mellados o machacados, puntos negros alineados para simbolizar zonas pulidas $\mathrm{y}$

9 La representación de los artefactos zamoranos se recoge en pp. 239 a 247 y en el anexo II de la tesis doctoral de uno de nosotros (RVG): Análisis de las transformaciones sociales en la Prehistoria reciente de la Meseta Norte Española (milenios VI-III cal a.C.) a través del empleo de la variscita y otros minerales verdes como artefactos sociotécnicos (disponible en http://uvadoc.uva.es/handle/10324/16693) y la de los onubenses en la web http://www.carlos.odriozola.us.es/ documentos. grandes flechas blancas para simbolizar la presencia y dirección de pseudorretoques (Figs. 7 y 8).

Hay que decir que, pese a que técnica y forma son variables objetivas, la función es una interpretación que hemos realizado en cada caso a partir de la forma, de la disposición de las distintas UTF en cada artefacto y de las huellas de uso identificadas. Así, hemos entendido que un útil con una UTF plana en un extremo y una UTF apuntada y con huellas de uso de tipo machacado y/o pulido en el otro, probablemente, haya sido utilizado a modo de cincel, recibiendo energía en su zona plana y perpendicular al eje para transformar materia con su zona apuntada y alineada con el eje (vid. ps6, ps9, FI, F2 o PC94). De forma similar, hemos considerado que una UTF localizada en un espacio intermedio entre otras de Cт у CR, rodeando al eje alrededor de su zona central y con forma de escotadura, probablemente haya funcionado para facilitar el enmangue (vid. PC51 o pc117). En los casos en los que hemos creído identificar la función con claridad lo hemos representado en los dibujos empleando el código 'CT', 'CR' o 'CP', pero en las ocasiones en las que esto se ha limitado a una mera sospecha, hemos optado por indicarlo con la presencia de un interrogante: 'CT?', 'CR?' O 'CP?'. 


\subsection{Algunas características de los conjuntos instrumentales de Peña el Sierro, Los Fornicos II y Pico Centeno identificadas a través de las UTF}

\subsubsection{Tipos de utF: de Contacto Transformativo (Ст), de Contacto Receptivo de Energía (CR) y de Contacto Prensil (CP)}

A partir de los criterios expuestos en el punto anterior hemos clasificado los distintos tipos de UTF apreciables en los artefactos mineros de Zamora y Huelva. Como uTF de contacto transformativo (UTF Ст) priman las afiladas (af) y apuntadas (ap), pero también existen casos de convexas (cn). Las afiladas se documentan en 38 (el 95\%) de los utensilios de Peńa el Sierro (e. g. PSi 8, ps28), en los 53 (100\%) de los de Los Fornicos II (e. g. F36, F46) y en 21 (el 53\%) de los de Pico Centeno (e. g. PC25, pc100), y prácticamente todas ellas están elaboradas mediante la talla por retoque simple (ctrs) a excepción de 3 de los casos de Pico Centeno, que cuentan con partes afiladas que aprovechan la propia forma de la corteza natural (PC21) o que se han obtenido mediante retoque plano (PC93). Las apuntadas, por su parte, aparecen en 21 (el 53\%) de los útiles de Peña el Sierro (e. g. ps1, ps6), en 36 (el 68\%) de los de Los Fornicos II (F2, F9) y en tan sólo 6 (el 15\%) de los de Pico Centeno (e. g. PC94), y todas se han configurado a partir de la talla por retoque simple (ctrs) a excepción de 1 útil (PC90) que aprovecha la forma natural del nódulo. En último lugar, al respecto de las convexas debemos destacar que sólo las hemos identificado en los artefactos de Pico Centeno (e.g. PC29, Pc117), en concreto en 15 de ellos $(38 \%)$, de las cuales hay 10 en las que se aprovecha la forma natural de la corteza, 4 obtenidas mediante retoque simple y 3 a través del piqueteado.

Mientras que los conjuntos zamoranos se caracterizan por una presencia casi absoluta de UTF Ст afiladas que además se ven acompañadas en bastantes de los casos de UTF CT apuntadas, el de Pico Centeno muestra una distinción entre útiles que cuentan sólo con UTF CT afiladas -que suponen aproximadamente la mitad-, sólo con UTF CT convexas -aproximadamente un tercio- y sólo con UTF apuntadas -que se corresponde con la fracción restante-. Si consideramos que las UTF CT apuntadas han sido concebidas para aplicar la energía en un punto concreto, las afiladas a lo largo de una línea y las convexas en un plano, podríamos entender que su utilización habría sido a modo de picos, cuñas y martillos, respectivamente. Así, es posible apreciar que mientras que los útiles zamoranos se habrían concebido para ser empleados como cuñas (e. g. PS28, PS34, F40, F46) y, de forma accesoria, picos (e. g. PS2, Ps8, F9, F35), los de Pico Centeno se muestran algo más variados, al presentarse tres subconjuntos diferenciados que serían el de cuñas (e. g. PC2I, PC5I, PC93), el de picos (e. g. PC9O, PC94) y el de martillos (e. g. PC29, PCi 17). A favor de esta interpretación se puede aducir que el subconjunto de útiles de Pico Centeno con UTF CT convexas es significativamente más pesado que el del resto de artefactos del mismo yacimiento $(\mathrm{p}<$ $0,01)^{10}$ : mientras que los picos y cuñas son herramientas cuya acción se enfoca en un punto o una línea, el martillo sacrifica precisión a cambio de enfocarse en la transmisión de más energía. El hecho de que nuestros pretendidos martillos sean más pesados permitiría que cumplieran mejor esa función.

En cuanto a las UTF de contacto receptivo de energía (UTF CR) hay que decir que las hemos identificado en aproximadamente la mitad de los útiles de cada yacimiento, que son fundamentalmente de morfología plana $(\mathrm{pl})$, y que se han obtenido en proporción similar mediante el aprovechamiento de planos naturales de la corteza (n) o a través del retoque abrupto (ctra). Así, 19 (el 48\%) de las herramientas de Peńa el Sierro, 35 (el 66\%) de las de Los Fornicos in y 25 (el 63\%) de las de Pico Centeno cuentan con este tipo de UTF CR (e. g. Ps11, F1, PC21). De forma mucho más reducida nos encontramos con UTF CR de morfología convexa (cn), presente en 2 útiles (el 5\%) de Peña el Sierro-ps 18 y ps19, en ambos casos corteza natural-y en 7 (el 17\%) de los de Pico Centeno -tanto cortezas naturales como piqueteado (e. g. PC29)-.

Aquí podemos introducir un grupo de posibles UTF CR que, debido a su morfología afilada, no las

${ }^{10}$ Este es el resultado de aplicar una prueba u de MannWhitney con el software PAST 3.0. 

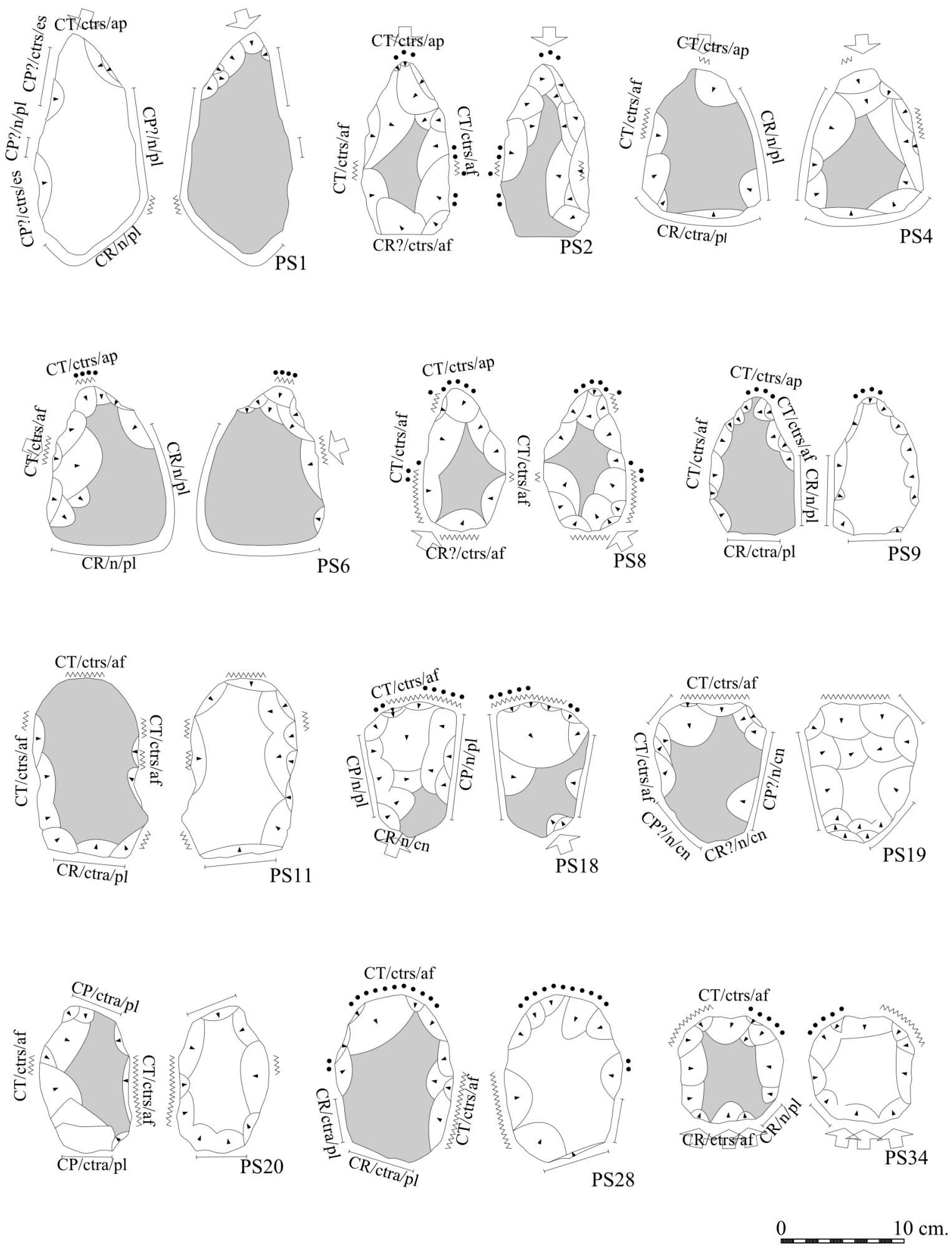

Fig. 4. Selección de artefactos de piedra tallada recuperados en Peña el Sierro (Palazuelo de las Cuevas, Zamora). 

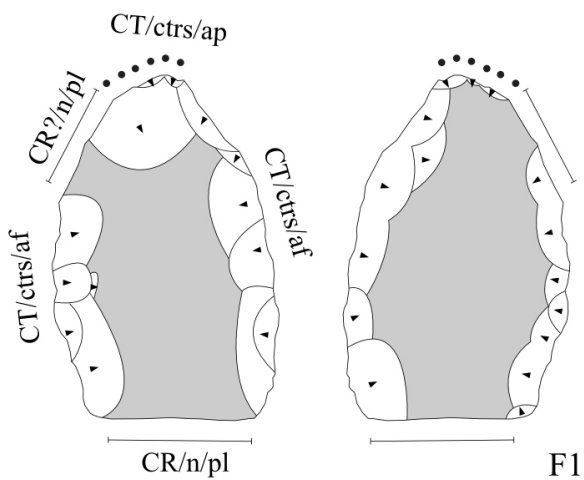

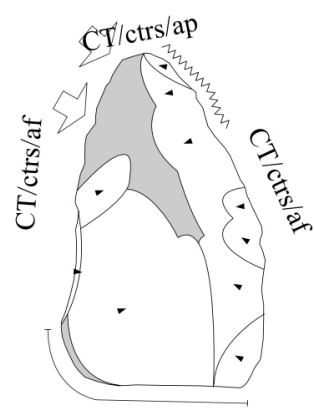

$\mathrm{CR} / \mathrm{n} / \mathrm{pl}$

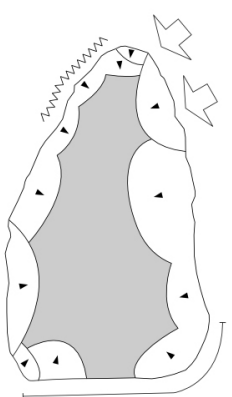

F2
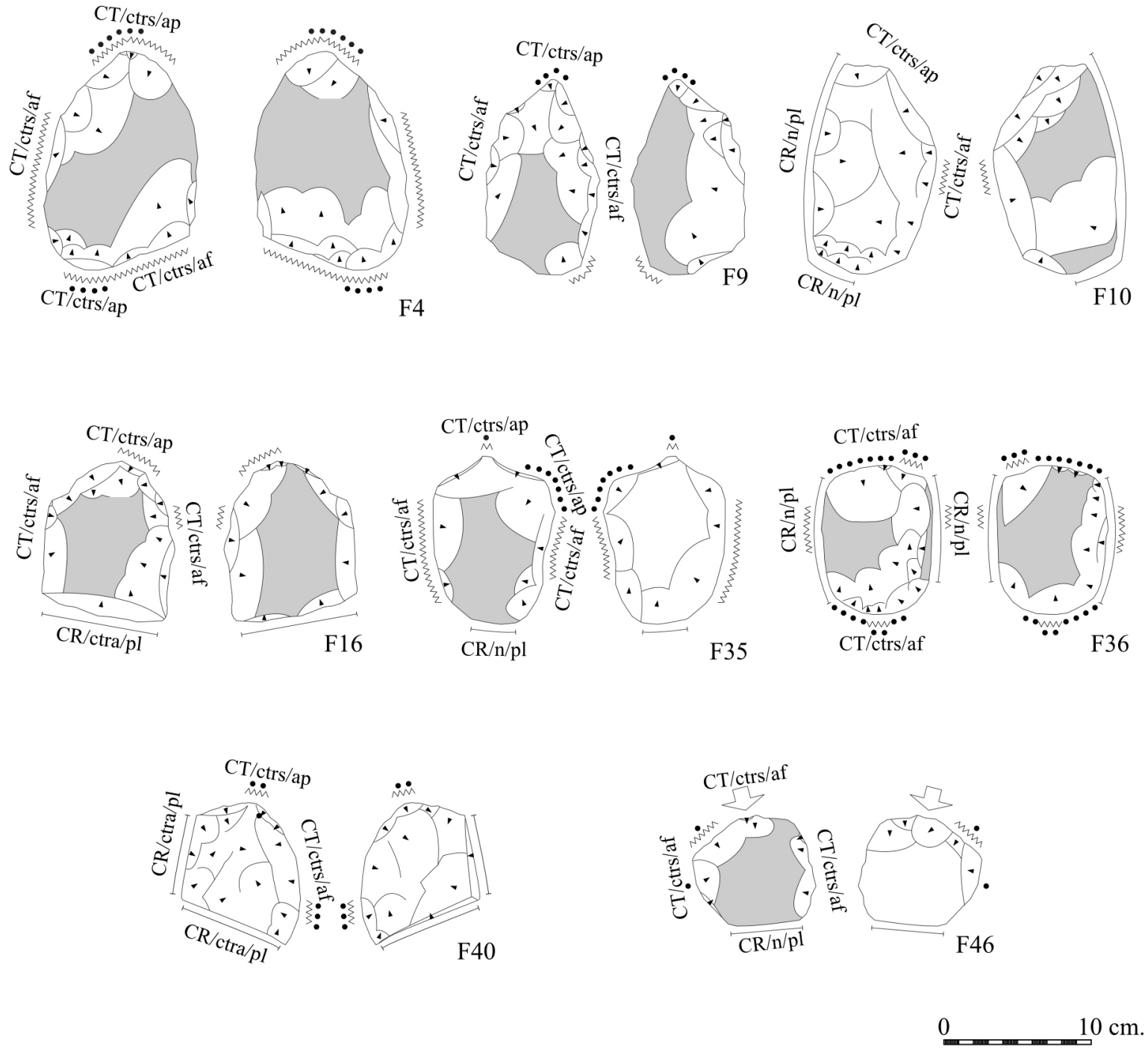

FIg. 5. Selección de artefactos de piedra tallada recuperados en Los Fornicos II (Palazuelo de las Cuevas/San Vicente de la Cabeza, Zamora). 

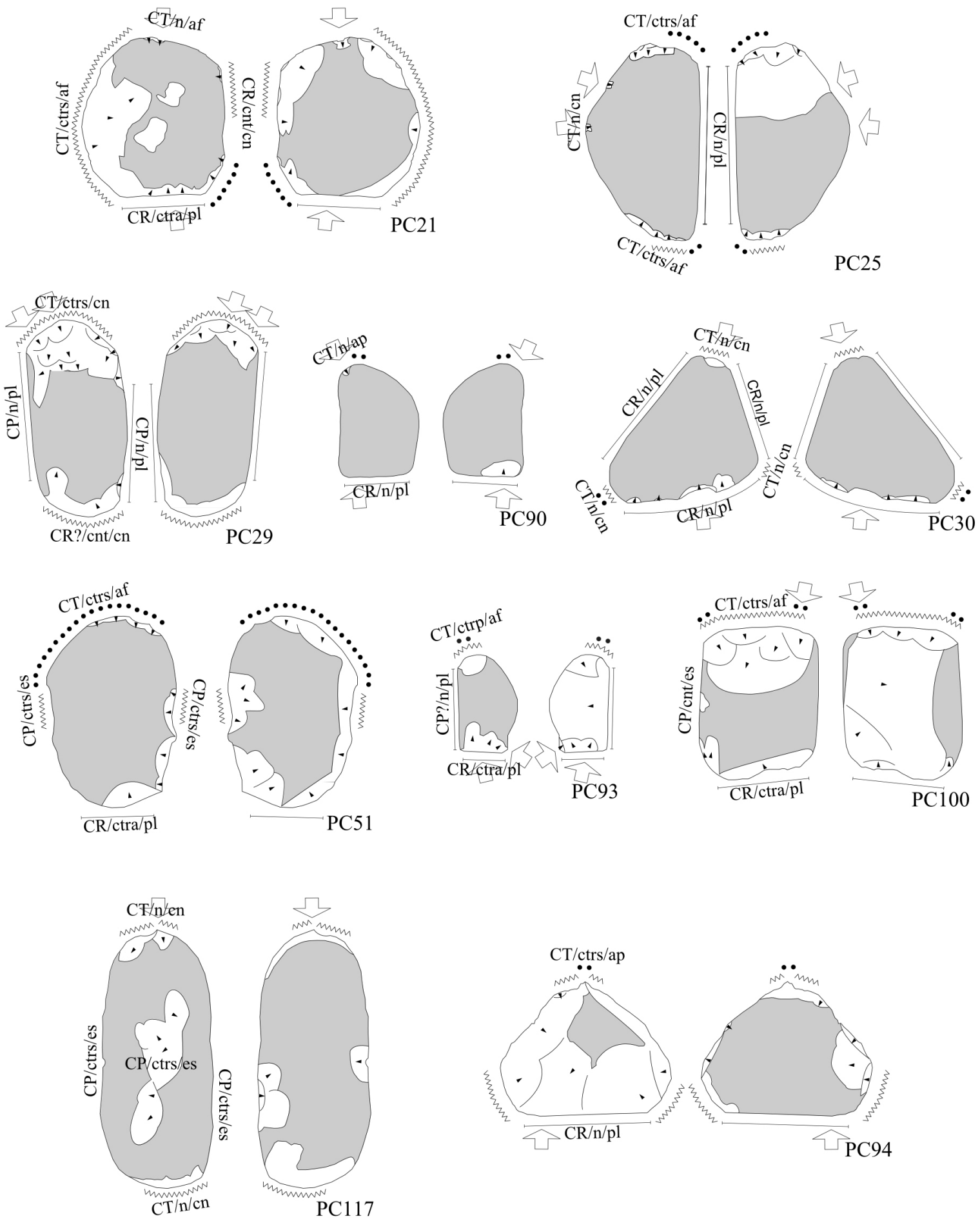

Fig. 6. Selección de artefactos de piedra tallada recuperados en Pico Centeno Mina 2 (Encinasola, Huelva). 
consideramos del todo adecuadas para ejercer tal función. No obstante, hay herramientas en las que una UTF afilada aparece en el extremo opuesto a una UTF apuntada, y dado que un extremo apuntado resulta totalmente inoperante para recibir energía hemos considerado, por descarte, que la parte receptiva sería la opuesta. Aun así, nuestras dudas nos han llevado a representarlas en los dibujos como "CR?/ ctrs/af”. Aparecen en 19 (el 40\%) de los útiles de Peña el Sierro, 12 (el 23\%) de los de Los Fornicos II y tan sólo 1 (el 3\%) de los de Pico Centeno.

En último lugar tenemos a las UTF de contacto prensil (UTF CP), presentes en proporciones mucho más reducidas que las dos anteriores. En cuanto a escotaduras (es) dispuestas alrededor del eje de funcionamiento de los útiles sólo hay 1 entre los artefactos zamoranos (PS1). En cambio, este tipo de UTF es más abundante en el conjunto de Pico Centeno, donde se presenta en un total de 8 (el 20\%), en los cuales se habrían obtenido mediante retoques simples en todos los casos salvo en 1 (PC100), donde se realizó mediante piqueteado. Otras posibles UTF CP son aquellas en las que el eje se ve rodeado no por una serie de escotaduras sino, en cambio, de distintas superficies planas (pl) contrapuestas que posiblemente sirvieran para favorecer el agarre. De estas hay 2 (el 5\%) entre los artefactos de Peña el Sierro (ps18 y ps20), 1 (el 2\%) entre los de Los Fornicos II (F36) y, de forma más abundante, 17 (el $43 \%$ ) entre los de Pico Centeno (e. g. ps29), que se conformaron en todos los conjuntos en similar proporción mediante el aprovechamiento de planos naturales de la corteza (n) y/o a través de retoques abruptos (ctra).

\subsubsection{Combinaciones de varias UTF CT en un mismo útil}

Como comentamos al respecto de la clasificación del utillaje minero por tipos de herramientas (punto 3.2), entre nuestros materiales se da el hecho de que en un mismo artefacto coexisten UTF Ст de distinta forma y, asumiendo la distinción que hemos realizado para su aptitud para ser empleadas como picos, cuñas y martillos, también de distinta funcionalidad. Contamos con útiles con dos UTF CT dispuestas en cada uno de los extremos del eje longitudinal de la pieza de tal forma que una se halla opuesta a la otra y ambas con la misma forma y, por tanto, misma función. Esto es lo que Timberlake y Craddock (2013) denominan, para los martillos, "Type AA" o "double-end mining hammers". Sólo hay un útil que cuente con dos UTF CT opuestas de morfología apuntada ( $\mathrm{F} 4$ ), pero son más abundantes los casos de morfología convexa y afilada. En cuanto los útiles con dos UTF Cт convexas contrapuestas, que habrían actuado a modo de esos 'martillos dobles' (PC29, PC117, etc.), supondrían la mitad de los útiles con utf Cт convexas de Pico Centeno -recordemos que no hay UTF CT convexas en los conjuntos zamoranos-. Pero lo que, si siguiéramos esta nomenclatura, serían "cuñas dobles", no suelen aparecer simplemente como tal sino combinadas con otras disposiciones de UTF también funcionales, en lo que podría denominarse 'útiles múltiples', que describimos a continuación.

Así, entre nuestros conjuntos de artefactos mineros hay varios útiles que cuentan con dos configuraciones de UTF distribuidas a lo largo de distintos ejes y totalmente funcionales cada una de forma independiente. Se corresponden a este proceder aquellas piezas que cuentan en su eje longitudinal con una configuración funcional -e. g. una UTF CT apuntada en un extremo y una UTF CR plana en el otro- y otra distinta y también funcional en el eje transversal, como pueden ser UTF CT afiladas contrapuestas a UTF CR planas (PS4, F10, PC25, etc.) o dos UTF CT afiladas contrapuestas entre sí (Ps11, F16, etc.). De este modo se hace posible que existan no sólo lo que se podrían denominar 'picos-cuña' y 'martillos-cuña', sino, también, lo que serían 'cuñas múltiples'. También debemos apuntar que hemos documentado el caso único de un útil que cuenta con tres configuraciones de UTF funcionales ( Ст/n/ cn frente a cR/n/pl) y que es PC30, lo que le haría lo que se podría denominar un 'martillo triple'.

Sin embargo, la presencia de estos útiles compuestos no tiene el mismo peso en los tres conjuntos. Mientras que en Peña el Sierro y Los Fornicos II 

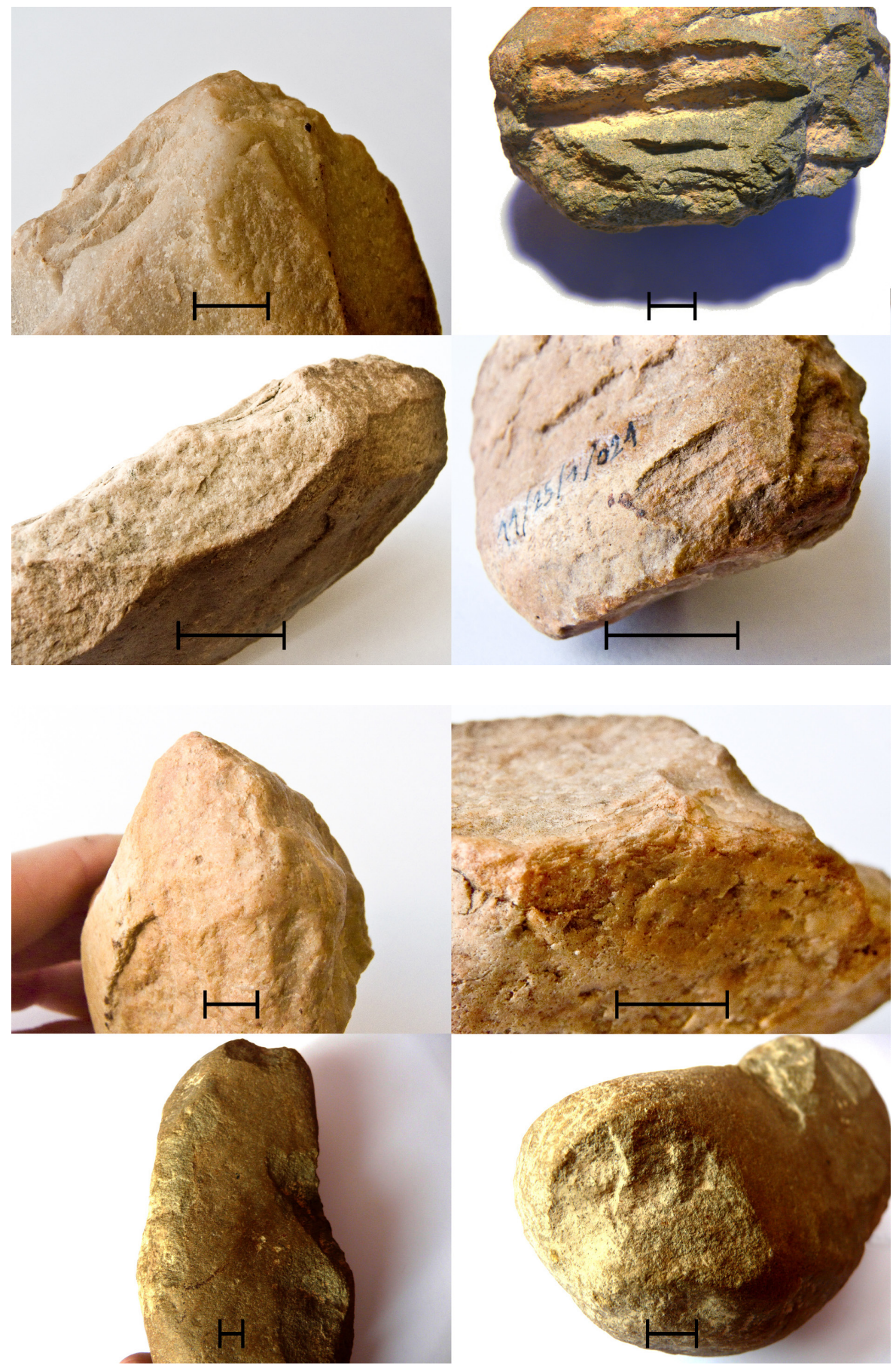

FIG. 7. Fotografías de detalle de varios artefactos: arriba izda. UTF CT/ctrslap con huellas de uso de tipo pulido (F4); arriba dcha. UTF CT/ctrslaf con huellas de uso de tipo mellado y pulido (PCG); abajo izda. UTF CR/n/pl y CR/ctra/pl (F31); abajo dcha. UTF CR?/ctrs/ af con huellas de uso de tipo pseudorretoque (PS21). La escala gráfca representa aproximadamente $1 \mathrm{~cm}$ en todos los casos.

FIG. 8. Fotografias de detalle de varios artefactos: arriba izda. UTF CT/ctrslaf con huellas de uso de tipo pulido (PS21); arriba dcha. UTF CT/ctrslaf con huellas de uso de tipo mellado (F5); abajo izda. UTF CP /ctrsles para el agarre (PC117); abajo dcha. UTF CT In/ cn con huellas de uso de tipo machacado y pseudorretoque (PC117) - véase también, en segundo plano, la ubicación de la escotadura para el agarre representada en la fotografía anterior-. La escala gráfica representa aproximadamente $1 \mathrm{~cm}$ en todos los casos. suponen el $88 \%$ y el $91 \%$ respectivamente del total de los utensilios mineros -entre los que hay aproximadamente en la misma proporción de artefactos en los que se combinan UTF CT apuntadas con UTF CT afiladas y de artefactos en los que combinan
UTF CT afiladas con UTF CT afiladas-, la frecuencia se reduce hasta el 18\% en el caso de Pico Centeno. No obstante, hay que apuntar que en las UTF CT afiladas de 4 (el 16\%) de los 'picos-cuña' de Peña el Sierro y de 9 (el 29\%) de los de Los Fornicos II 
no se aprecian huellas de uso. Por ello entendemos que, aunque fueran diseñados para cumplir las dos funciones, probablemente sólo una de ellas, la de pico, fuera la principal.

\subsection{3. Útiles mineros en proceso de elaboración}

De entre los artefactos procedentes de los yacimientos zamoranos y onubense hay varios que, atendiendo a distintas circunstancias, nos indican que han llegado a nosotros, bien en proceso de producción, o bien concluidos, pero sin marcas de haber sido utilizados (Fig. 9). PC118, PC103, ps40 y Ps41 son objetos que no ofrecen la misma silueta que el resto de herramientas de sus respectivos conjuntos y parece bastante claro que les falta parte del proceso de manufactura: en el caso de PC118 restaría posiblemente una mayor dedicación a lo que parece un esbozo de UTF CR plana y la configuración completa de lo que sería la UTF CT, y PC103 muestra varias potenciales UTF CR, pero, según parece, no llegó a concluirse ninguna UTF CT apropiada. En cuanto a Ps 40 y ps41 queremos apuntar la similitud que guardan con alguno de los esbozos de hachas pulimentadas identificados en otros contextos peninsulares (e. g. Risch y Martínez Fernández, 2008: figs. 3-5);
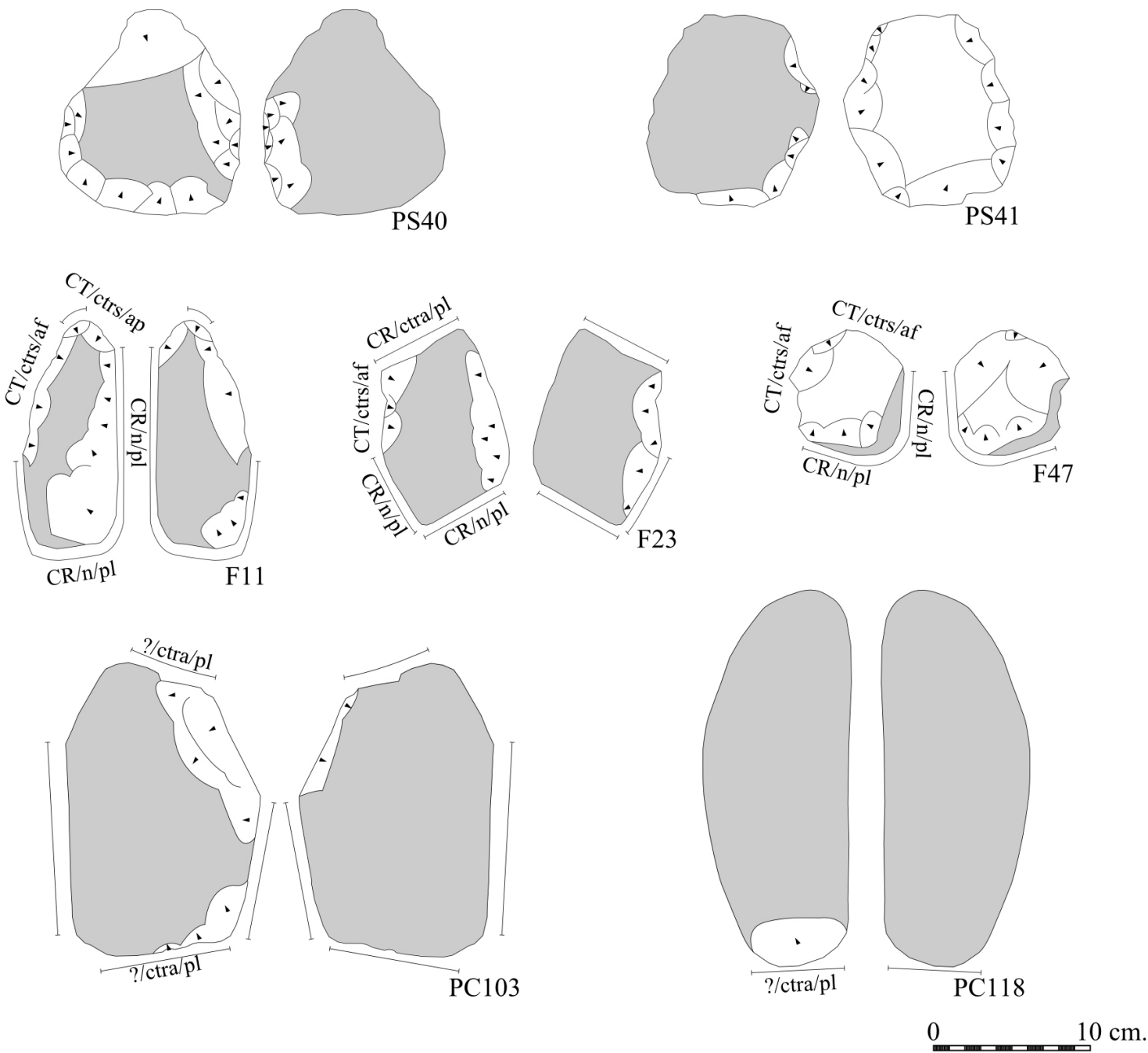

FIG. 9. Artefactos en proceso de elaboración recuperados en los tres yacimientos. 
probablemente les falte un trabajo de retoque simple bifacial para completar la delineación de la silueta, así como, también, una más detallada configuración de sus distintas UTF. Además, ninguno de estos -PC103, PC118, ps40 y ps41- cuenta con huellas de uso de ningún tipo. En segundo lugar hay otros que sí que parecen haberse concluido, como F11, F23 y $\mathrm{F} 47$, pero la total ausencia de huellas de uso nos sugiere que no llegaron a ser utilizados.

La presencia de útiles en proceso de elaboración y de útiles todavía no utilizados, junto con la recuperación -en los yacimientos zamoranosde pequeños percutores y alguna pequeña lasca de cuarcita (Fig. 10), son pruebas que apuntan a la manufactura in situ de los artefactos mineros. Ya
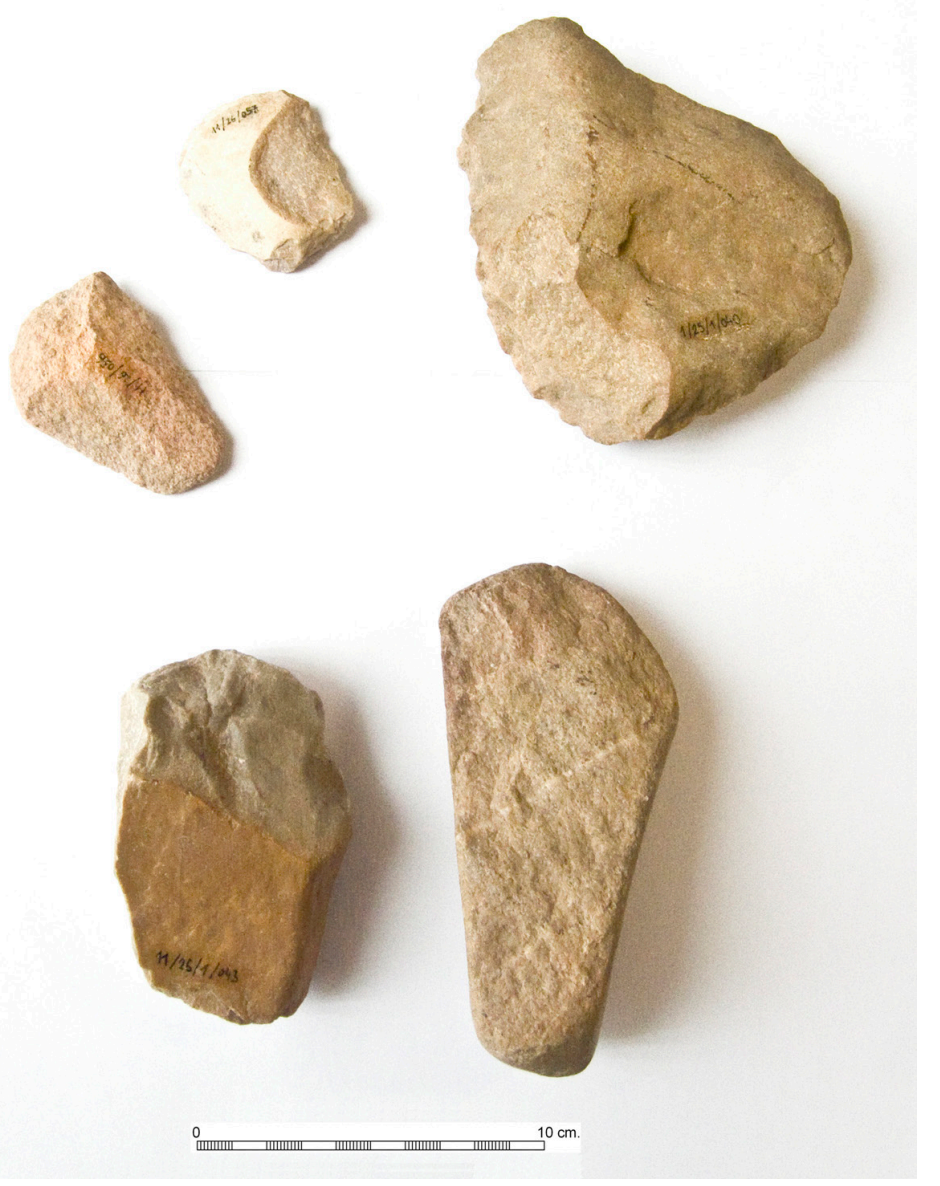

FIG. 10. Distintos objetos representativos del proceso de manufactura procedentes de los yacimientos zamoranos: arriba izqda. lascas resultado de la talla; arriba dcha. utensilio en proceso de tallado; abajo percutores. hemos mencionado la existencia de afloramientos naturales de cuarcita en puntos no muy alejados de cada uno de los yacimientos, por lo que es presumible que la cadena operativa completa de los útiles mineros -obtención de materia prima, elaboración, uso y abandono- se desarrollara por completo en el entorno cercano de las minas de variscita.

\section{La tecnología empleada en la minería prehistórica de variscita en Palazuelo de las Cuevas y Pico Centeno}

El análisis conjunto de estos materiales de piedra tallada empleados en la minería de variscita nos ha permitido identificar, entre ambos grupos, varias similitudes. Pero, también, hemos advertido importantes diferencias.

En ambos casos la materia prima preferida es la cuarcita, una roca asequible en los alrededores de las minas zamoranas y de las onubenses y que fue empleada para manufacturar las herramientas probablemente a pie de mina. El análisis de Unidades Tecno-Funcionales nos ha permitido identificar que se produjeron actuaciones sobre los útiles encaminadas a la configuración de UTF de contacto transformativo (CT), UTF de contacto receptivo de energía (CR) y UTF de contacto prensil (CP) mediante el aprovechamiento de las formas naturales de los nódulos, de la aplicación de retoques simple $\mathrm{y}$ abruptos $\mathrm{y}$, en menor medida, del piqueteado.

Por otro lado, las diferencias radican en que los útiles de Pico Centeno son significativamente más pesados que los zamoranos y que en cada caso la configuración se ha orientado a la obtención de un conjunto de herramientas ligeramente diferente. Aunque en todos los yacimientos haya 
útiles compuestos e, incluso, útiles compuestos que ofrecen varias funciones -que en un sentido pudieron trabajar como cuñas y en otro como picos o martillos-, estos son mucho más abundantes en los conjuntos zamoranos. Mientras que en Pico Centeno la mayoría de los artefactos se encuentran elaborados para ser usados de una manera y para una tarea específica, en Peña el Sierro y Los Fornicos II la mayor parte de los útiles son multifuncionales, bien cuñas en distintos ejes, o bien picos-cuña. Otra diferencia es que en los yacimientos zamoranos no hay UTF Ст convexas, que serían aquellas que permitirían a los útiles funcionar como martillos, y que en cambio se encuentran bien representadas en el conjunto de Pico Centeno.

En todos los aspectos analizados los dos yacimientos zamoranos coinciden casi a la perfección, lo que permite plantear que quienes explotaron la variscita del cerro de Las Cercas (Peña el Sierro) y del de La Cogolla (Los Fornicos II) fueron o bien el mismo grupo, o bien personas de distintos grupos, pero que compartían un mismo proceder tecnológico. Sin embargo, son bastantes las diferencias entre la tecnología de los mineros de Palazuelo de las Cuevas y los de Pico Centeno.

¿A qué se deberían, por tanto, las distintas soluciones tecnológicas identificadas en la producción de los conjuntos de útiles zamoranos y el onubense? Varias pueden ser las explicaciones.

Una de ellas podría ser el que el tipo de roca encajante puede determinar tanto la morfología de la mina como el tipo de utillaje preciso para el minado (Borkowski, 1995). Sin embargo, tanto en la comarca de Aliste como en los alrededores de Encinasola el contexto geológico -rocas encajantes síliceas-, forma de las mineralizaciones -horizontales y orientadas con dirección N100E-, etc., son circunstancias prácticamente idénticas (Moro et al., 1995) que, a su vez, son radicalmente distintas de las que se presentan en las minas de Barcelona (Villalba et al., 1998).

Otra explicación sería que hubiera distintas estructuras mineras. Sin embargo, tanto en Aliste como en Encinasola predominan las trincheras y otras minas mayoritariamente superficiales
(Odriozola y Villalobos García, 2015) ${ }^{11}$, al contrario de como sucede en el caso barcelonés, donde las labores fueron fundamentalmente subterráneas (Villalba et al., 1998).

Una tercera posibilidad sería explicar las diferencias como resultado de una explotación en distintas épocas. Fechar una mina prehistórica es una labor complicada (Hunt, 1996) y, como explicamos en el punto 2, nuestros yacimientos no son una excepción ( $c f$. también Odriozola et al., 2016). Por ello, con objeto de afinar en esta cuestión, podemos rastrear la cronología del uso del material explotado. Existen determinadas características compositivas en la variscita que permiten discriminar si un adorno prehistórico provendría del filón de Aliste o del de Encinasola (Odriozola et al., 2010a), y los análisis de composición realizados hasta la fecha muestran que en el Oeste peninsular resultan mucho más abundantes los adornos prehistóricos de variscita alistana (Odriozola et al., 2012, 2013a, 2013b; Odriozola y García Sanjuán, 2013). No obstante, los contextos de consumo de adornos de variscita onubense conocidos (Odriozola et al., 2010b) son adscribibles a la primera mitad del III milenio cal a. C. (Valera et al., 2000), lo cual es totalmente coincidente con el momento de máximo apogeo de la explotación prehistórica de variscita zamorana (Villalobos y Odriozola, 2016). Por lo tanto, no hay pruebas para defender que necesariamente hubiera habido una diferencia cronológica entre ambas explotaciones.

Dado que ni el contexto geológico, las formas de minado o la cronología muestran diferencias claras, creemos posible hallar la respuesta al introducir la variable de la escala de la explotación. Como decíamos, parece que durante la Prehistoria reciente la variscita alistana habría sido distribuida de forma más amplia y en mayor cantidad que la onubense. Esto es algo que puede relacionarse con la cuantía de las labores mineras identificadas. Frente al total de 4 trincheras de entre 6 y $20 \mathrm{~m}$ de longitud documentadas en Encinasola (Odriozola y Villalobos, 2015), en los cerros zamoranos de Las Cercas y La Cogolla

11 Villalobos y Odriozola, op. cit. n. 2. 
se identifican en torno a una veintena de pozos y trincheras, extendiéndose las cinco más grandes de estas últimas a lo largo de entre 200 y $470 \mathrm{~m}$ de longitud cada una ${ }^{12}$. Si bien es posible que parte de las minas zamoranas sean resultado de la explotación romana (Gutiérrez Pérez et al., 2015), la cantidad de útiles recogidos aconseja el no infravalorar la cuantía de las labores prehistóricas: en la prospección superficial previa a la excavación de PCM2 tan sólo se recuperaron una veintena de artefactos ${ }^{13}$, mientras que la prospección superficial de Peña el Sierro y Los Fornicos II ofreció medio centenar de ellos en cada caso. Incluso puede considerarse que el número de artefactos recogidos en Palazuelo de las Cuevas se hallaría infrarrepresentado debido a la visibilidad prácticamente nula que en 2011 nos encontramos en la mayor parte de la superficie de ambos cerros por causa de la densa vegetación de matorral. A este respecto resulta interesante apuntar que a comienzos de la década de los años 80 del s. Xx, cuando la superficie del cerro de La Cogolla se hallaba despejada casi en su totalidad al hallarse explotada por la agricultura cerealista ${ }^{14}$, se recogieron c. 600 artefactos que por entonces fueron interpretados como industrias paleolíticas, pero que, a tenor de las fotografías publicadas (Cuadrado, 1983), nos parecen asimilables al instrumental minero con el que hemos trabajado.

Por tanto, consideramos como la opción más probable que el factor que explique las diferencias tecnológicas entre los conjuntos de herramientas mineras sea el hecho de que las minas zamoranas fueran explotadas a una escala mucho mayor que las onubenses. Así, que el instrumental de Peña el Sierro y Los Fornicos II sea de tamaño más reducido y cuente con una presencia significativamente

12 Villalobos y Odriozola, op. cit. n. 2.

${ }^{13}$ Estos materiales, algunos de los cuales aparecen en una fotografía publicada con anterioridad (Odriozola et al., 2010: fig. 2), fueron identificados en una visita preliminar al lugar, pero debido a que no se recogieron no han formado parte del análisis realizado en este trabajo.

${ }^{14}$ Esta circunstancia se aprecia a la perfección en las fotografías aéreas tomadas durante el periodo 1977-1983, que el Instituto Tecnológico Agrario de Castilla y León ofrece para su consulta en ftp.itacyl.es (consultado 14-04-2014). mayor de útiles multifuncionales que el instrumental de Pico Centeno podría haber sido el resultado de la experiencia acumulada por los grupos que a lo largo de muchas repetidas incursiones se habrían dedicado a la extracción de la variscita zamorana.

Sin embargo, sea por este o por otros motivos, en todo caso parece bastante seguro que en Encinasola y la comarca zamorana de Aliste existieron dos tradiciones tecnológicas independientes. Esto nos faculta a plantear que, aunque los productos -adornos de variscita- se distribuyeran a escala suprarregional (Villalba et al., 2001; Domínguez-Bella, 2004; Querré et al., 2012; Odriozola et al., 2013) $)^{15}$, los grupos responsables de la explotación de los distintos afloramientos no habrían llegado a interactuar, al menos de forma significativa, entre sí.

\section{Bibliografía}

Abarquero, F. J. y Guerra, E. (eds.) (2010): Los yacimientos de Villafáfila (Zamora) en el marco de las explotaciones salineras de la prehistoria europea. Valladolid: JCyL.

Alonso, M.; Edo i Benaiges, M.; Gordo, L.; Millán, M. y Villalba, M. J. (1978): “Explotación minera neolítica en Can Tintoré (Gavà, Barcelona)", Pyrenae, 13-14, pp. 7-14.

http://www.raco.cat/index.php/Pyrenae/article/ view/164938 (01-12-2015).

Arribas, A.; Galán, E.; Martín-Pozas, J. M.; Nicolau, J. y Salvador, P. (1971): "Estudio mineralógico de la variscita de Palazuelo de las Cuevas, Zamora (España)", Studia Geologica Salmanticensia, 2, pp. 115-132.

Blanco Freijeiro, A. y Rothenberg, B. (1981): Exploración Arqueometalúrgica de Huelva (EAH). Barcelona: Labor.

BLAs, M. Á. (2011): "Las minas prehistóricas del norte de España en el contexto de la paleominería del cobre del Occidente de Europa”. En Mata-Perelló, J. M.; Torró, L. y Fuentes, M. N. (eds.): Actas v Cong. Int. sobre minería y metalurgia históricas en el suroeste europeo. Madrid: SEDPGYM, pp. 101-130.

15 También Villalobos, R.: Análisis de las transformaciones sociales en la Prehistoria Reciente de la Meseta Norte Espanola (milenios VI-III cal a.C.). Valladolid: Univ. Valladolid, en prensa, cap. 3.4.1. 
Blas, M. Á. y SuÁrez, M. (2009): “Utillaje faunístico inédito de las labores de cobre prehistóricas de La Profunda (León) y su datación C14 (AMs)", Zephyrus, LXIV, pp. 5-18.

http://revistas.usal.es/index.php/0514-7336/article/ view/7205 (01-03-2013).

BofILl, M. y Borrell, F. (2009): "Utillatge macrolític neolític de les mines 83, 84, 85 i 90 de Gavà". En Bosch, J. y Borrell, F. (eds.): Intervencions arqueologiques a les Mines de Gavà (sector serra de les Ferreres). Anys 1998-2009. Gavà: Museu de Gavà, pp. 139-147.

Borkowski, W. (1995): “Éléments d'analyse du système d'aménagement d'une minière: l'exemple de Krzemionki”. En Pelegrin, J. y Richard, A. (eds.): Les mines de silex au Néolithique en Europe: avancées récentes. Paris: Стнs, pp. 67-72.

Bosch, J. y Borrell, F. (eds.) (2009): Intervencions arqueològiques a les Mines de Gavà (sector serra de les Ferreres). Anys 1998-2009. Gavà.

Campano, A.; Rodríguez Marcos, J. A. y Sanz MínGUEZ, C. (1985): "Apuntes para una primera valoración de la explotación y comercio de la variscita en la Meseta Norte", Anuario del Instituto de Estudios Zamoranos Florián de Ocampo, 1985, pp. 13-22.

Capote, M. (2011): "Working in the flint mine: Percussion tools and labour organisation at Casa Montero (Spain)". En Capote, M.; Consuegra, S.; DíazDel-Río, P. y Terradas, X. (eds.): Proceedings 2nd International Conference of the UISPP Commission on Flint Mining in Pre-and Protohistoric Times. Oxford: Archaeopress, pp. 231-242.

Capote, M.; Castañeda, N.; Consuegra, S.; Criado, C. y Díaz-Del-Río, P. (2008): "Flint mining in Early Neolithic Iberia: A preliminary report on 'Casa Montero’ (Madrid, Spain)”. En Allard, P.; Bostyn, F.; Giligny, F. y Lech, J. (eds.): Flint Mining in Prehistoric Europe. Interpreting the archaeological records. Oxford: Archaeopress, pp. 123-137.

Craddock, P. T. (1995): Early Metal Mining and Production. Edinburgh: EUP.

Cuadrado, E. (1983): "La industria de cantos trabajados del río Aliste (Zamora)", Boletín de la Asociación Española de Amigos de la Arqueología, 17, pp. 30-37.

Delibes de Castro, G.; Fernández Manzano, J. y Herrán, J. I. (2003): "Notas sobre minería y metalurgia calcolíticas en la Submeseta Norte Española". En Fernández Manzano, J. y Herrán, J. I. (eds.): Mineros y fundidores en el inicio de la Edad de los Metales. El Midi francés y el Norte de la península Ibérica. León: Caja España, pp. 120-132.
Domergue, C. (1990): Les mines de la péninsule Ibérique dans l'Antiquité Romaine. Roma: EFR.

Domergue, C. (2008): Les mines antiques. La production des métaux aux époques grecque et romaine. Paris: Picard.

Domínguez-Bella, S. (2004): "Variscite, a prestige mineral in the Neolithic-Aeneolithic Europe. Raw material sources and possible distribution routes", Slovak Geological Magazine, 10 (1-2), pp. 147-152.

Donnart, K. (2010): "L'analyse des unités techno-fonctionnelles appliquée à l'étude du macro-outillage néolithique", L'Anthropologie, 114 (2), pp. 179-198. http://doi.org/10.1016/j.anthro.2010.03.001 (01-122015).

Fernández Turiel, J. L.; Gimeno, D.; López Soler, A. y Querol, X. (1992): "Las mineralizaciones fosfáticas de los materiales paleozoicos de la provincia de Zamora", Anuario del Instituto de Estudios Zamoranos Florián de Ocampo, 1992, pp. 463-506.

Forde, C. D. (1930): "On the Use of Greenstone (Jadeite, Callais, etc.) in the Megalithic Culture of Brittany", The Journal of the Royal Anthropological Institute of Great Britain and Ireland, 60, pp. 211-234. http://doi.org/10.2307/2843867 (24-02-2014).

Garcia-Guinea, J.; Sapalski, C.; Cardenes, V. y LomBARDERO, M. (2000): "Mineral inlays in natural stone slabs: techniques, materials and preservation", Construction and Building Materials, 14 (6-7), pp. 365-373. http://doi.org/10.1016/S0950-0618(00)00047-7 (24-01-2014).

Gutiérrez Pérez, J.; Villalobos, R. y Odriozola, C. P. (2015): "El uso de la variscita en Hispania durante la Época Romana. Análisis de composición de objetos de adorno y teselas de la zona noroccidental de la Meseta Norte", Spal, 24, pp. 165-181.

http://dx.doi.org/10.12795/spal.2015i24.07 (01-122015).

Hunt, M. A. (1996): "Prospección arqueológica de carácter minero y metalúrgico: fuentes y restos”, Acontia, 2, pp. 19-28.

Hunt, M. A. (2003): Prehistoric mining and Metallurgy in South West Iberian Peninsula. Oxford: Archaeopress.

Hunt, M. A.; Consuegra, S.; Díaz del Río, P.; Hurtado, V. y Montero, I. (2011): "Neolithic and Chalcolithic -VI to III millenia BC- use of cinnabar (Hgs) in the Iberian peninsula: analytical identification and lead isotope data for an early mineral exploitation of the Almadén (Ciudad Real, Spain) mining district”. En Ortiz, J. E.; Puche, O.; Rábano, I. y Mazadiego, L. F. (eds.): History of research in mineral resources. Madrid: IGME, pp. 3-13. 
Montero, I. (2010): “Tecnología de la metalurgia de la base cobre". En Montero, I. (ed.): Manual de Arqueometalurgia. Alcalá de Henares: MAR, pp. 159-188.

Moro, M. C.; Gil, M. D.; Cembranos, M. L.; Pérez del Villar, L. y Fernández, A. (1995): "Las mineralizaciones estratiformes de variscita (Aluminofosfatitas) silúricas de los Sinformes de Alcañices (Zamora) y Terena (Huelva, España)", Boletín Geológico y Minero, 106 (3), pp. 33-49.

Moro, M. C.; Gil, M. D.; Montero, J. M.; Cembranos, M. L.; Pérez del Villar, L.; Fernández, A. y Hernández, E. (1991): "Las mineralizaciones de variscita asociadas a los materiales volcano-sedimentarios silúricos del Sinforme de Terena, Encinasola (prov. de Huelva)", Boletín de la Sociedad Española de Mineralogia, 14 (1), pp. 101-102.

Nocete, F. y Linares, J. A. (1999): "Las primeras sociedades mineras en Huelva”. En Jurado, J. M. y MárQuez, J. A. (dirs.): Historia de la provincia de Huelva. Huelva: Mediterráneo, vol. 1, pp. 49-64.

Odriozola, C. P. y García Sanjuán, L. (2013): "Las cuentas de collar de piedra verde de Matarrubilla (Valencina de la Concepción, Sevilla)". En García Sanjuán, L.; Vargas, J. M.; Hurtado, V.; Ruiz Moreno, T. y Cruz-Auñón, R. (eds.): El asentamiento prehistórico de Valencina de la Concepción (Sevilla): Investigación y Tutela en el 150 Aniversario del Descubrimiento de La Pastora. Sevilla: Univ. Sevilla, pp. 485-494.

Odriozola, C. P.; Linares, J. A. y Hurtado, V. (2010a): "Variscite source and source analysis: testing assumptions at Pico Centeno (Encinasola, Spain)", Journal of Archaeological Science, 37 (12), pp. 3146-3157. http://doi.org/10.1016/j.jas.2010.07.016 (25-01-2013).

Odriozola, C. P.; Linares, J. A. y Hurtado, V. (2010b): "Perdigóes green beads provenance analysis", Apontamentos de Arqueologia e Patrimonio, 6, pp. 47-51.

http://www.nia-era.org/publicacoes/doc_download/6-apontamentos-6 (01-12-2015).

Odriozola, C. P.; Mataloto, R.; Moreno-García, J.; Villalobos, R. y Martínez-Blanes, J. M. (2012): "Producción y circulación de rocas verdes y sus productos en el sw peninsular: el caso de Anta Grande do Zambujeiro", Estudos Arqueológicos de Oeiras, 19, pp. 125-142.

Odriozola, C. P.; Sousa, A. C.; Boaventura, R. y Villalobos, R. (2013): "Componentes de adorno de pedra verde de Vila Nova de São Pedro (Azambuja): Estudo de proveniencias e redes de troca no
3 o milénio A.N.E. no actual territorio portugués". En Arnaud, J. M.; Martins, A. y Neves, C. (eds.): Arqueología em Portugal. 150 anos. Lisboa: Associação dos Arqueólogos Portugueses, pp. 457-462.

Odriozola, C. P. y Villalobos, R. (2015): "La explotación de variscita en el Sinforme de Terena: el complejo minero de Pico Centeno (Encinasola, Huelva)", Trabajos de Prehistoria, 72 (2), pp. 342-352. http://doi.org/10.3989/tp.2015.12158 (07-01-2016).

Odriozola, C. P.; Villalobos, R.; Boaventura, R.; Sousa, A. C.; Martínez-Blanes, J. M. y Cardoso, J. L. (2013): "Las producciones de adorno personal en rocas verdes del sw peninsular: los casos de Leceia, Moita da Ladra y Penha Verde", Estudos Arqueológicos de Oeiras, 20, pp. 605-622.

Odriozola, C. P.; Villalobos, R.; Burbidge, C. I.; Boaventura, R.; Sousa, A. C.; Rodríguez-Ariza, O.; Parrilla, R.; Prudêncio, M. I. y Dias, M. I. (2016): "Iberian Variscite mining and consumption: distribution and chronological framework from Pico Centeno (Encinasola, Spain)", Quaternary Reseach, 85, pp. 159-176. http://doi.org/10.1016/j.yqres.2015.11.010 (23-022016).

Querré, G.; Domínguez-Bella, S. y Cassen, S. (2012): "La variscite ibérique. Exploitation, diffusion au course du Néolithique". En Marchand, G. y Querré, G. (eds.): Roches et Sociétés de la Préhistoire. Entre massifs cristallins et bassins sédimentaires. Rennes: PUR, pp. 307-315.

Ramos Millán, A. (1998): "La minería, la artesanía y el intercambio de sílex durante la Edad del Cobre en el Sudeste de la Península Ibérica”. En Delibes de Castro, G. (ed.): Minerales y metales en la Prehistoria Reciente. Algunos testimonios de su explotación y laboreo en la peninsula ibérica. Valladolid: Univ. Valladolid, pp. 13-40.

Risch, R. y Martínez Fernández, F. (2008): “Dimensiones naturales y sociales de la producción de hachas de piedra en el Noreste de la Península Ibérica”, Trabajos de Prehistoria, 65 (1), pp. 47-71. http://doi.org/10.3989/tp.2008.v65.i1.135 (17-042014).

Roscian, S.; Claustre, F. y Dietrich, J. E. (1992): "Les parures du Midi Méditerranéen du Néolithique ancien à l'Âge du Bronze: origine et circulation des matières premières", Gallia préhistoire, 34, 209-257. http://doi.org/10.3406/galip.1992.2303 (03-022015). 
Tarriño, A.; Lobo, P. J.; García-Rojas, M.; Elorrieta, I.; Orue, I.; Benito, A. y Karampanglidis, T. (2011): "Introducción al estudio de las minas neolíticas de sílex de la Sierra de Araico (Condado de Trevińo): campaña de excavación del 2011”, Estudios de Arqueología Alavesa, 27, pp. 7-48.

Timberlake, S. y Craddock, B. R. (2013): "Prehistoric metal mining in Britain: the study of cobble stone mining tools based on artefact study, ethnography and experimentation", Chungara, 45 (1), pp. 33-59. http://www.chungara.cl/Vols/2013/45-1/Timberlake_y_Craddock_45-1-2013.pdf (06-06-2014).

Valera, A. C.; Lago, M.; Duarte, C. y Evangelista, L. S. (2000): "Ambientes funerários no complexo arqueológico dos Perdigóes: uma análise preliminar no contexto das práticas funerárias calcolíticas no Alentejo", Era Arqueologia, 2, pp. 84-105.

Villalba, M. J.; Bañolas, L.; Arenas, J. y Alonso, M. (1986): Les mines neolítiques de Can Tintorer, Gavà. Excavacions 1978-1980. Barcelona.
Villalba, M. J.; Edo i Benaiges, M. y Blasco, A. (1998): "Explotación, manufactura, distribución y uso como bien de prestigio de la calaita en el Neolítico. El ejemplo del complejo de Can Tintorer". En Delibes de Castro, G. (ed.): Minerales y metales en la Prehistoria Reciente. Algunos testimonios de su explotación y laboreo en la peninsula ibérica. Valladolid: Univ. Valladolid, pp. 41-70.

Villalba, M. J.; Edo i Benaiges, M. y Blasco, A. (2001): "La callaïs en Europe du Sud-Ouest. État de la question". En Le Roux, C.-T. (ed.): Du monde des chasseurs à celui des métallurgistes. Rennes, pp. 267-276.

Villalobos, R. y Odriozola, C. P. (2016): "Organizing the Production of Variscite Personal Ornaments in Later Prehistoric Iberia: The Mines of Aliste and the Production Sites of Quiruelas de Vidriales ( $\mathrm{Za}$ mora, Spain)", European Journal of Archaeology, 19. http://doi.org/10.1080/14619571.2016.1147316 (23-02-2016). 